\title{
Enabling 2.4-V aqueous supercapacitors through the rational design of an integrated electrode of hollow vanadium trioxide/carbon nanospheres
}

\author{
Kaiyang Zhang ${ }^{1 \dagger}$, Yingchun Lin ${ }^{1 \dagger}$, Lingfang Chen ${ }^{1}$, Jun Huang ${ }^{1}$, Li Wang ${ }^{1}$, Mengke Peng ${ }^{1}$, \\ Xiannong Tang ${ }^{1}$, Ting $\mathrm{Hu}^{2}$, Kai Yuan ${ }^{1^{*}}$ and Yiwang Chen ${ }^{1,3^{*}}$
}

\begin{abstract}
Aqueous supercapacitors (SCs) exhibit several advantages, including high-power density, cycling durability, and safety; however, the shortage of low energy density inhibits their further application. Acquiring an excellent performance upon using simple strategies would be beneficial, but remains challenging. Here, an integrated electrode of hollow $\mathrm{V}_{2} \mathrm{O}_{3}$ /carbon nanospheres $\left(\mathrm{H}-\mathrm{V}_{2} \mathrm{O}_{3} / \mathrm{C}\right)$ was designed and synthesized for SCs. The introduction of carbon can increase the conductivity and stability, whereas the hollow structure endows $\mathrm{H}-\mathrm{V}_{2} \mathrm{O}_{3} / \mathrm{C}$ with a high specific surface area and rapid transport of ions. Moreover, the $\mathrm{H}-\mathrm{V}_{2} \mathrm{O}_{3} / \mathrm{C}$ integrated electrode can simultaneously work in both negative and positive potential windows. Benefiting from these advantages, the $\mathrm{H}-\mathrm{V}_{2} \mathrm{O}_{3} / \mathrm{C}$ integrated electrode exhibits a specific capacitance as high as $708.6 \mathrm{~F} \mathrm{~g}^{-1}$ in a wide voltage window of -1.1-1.3 V. Furthermore, stemming from the multiple energy storage mechanisms, the aqueous integrated full SC device exhibits a wider potential window and higher energy density than the traditional (a)symmetric ones. Therefore, the proposed device delivers a wide voltage window of $2.4 \mathrm{~V}$ with an energy density of $96.8 \mathrm{~W} \mathrm{~h} \mathrm{~kg}^{-1}$ at a power density of $1204.6 \mathrm{~W} \mathrm{~kg}^{-1}$, as well as superior cycling stability. This study enlightens the design and preparation of electrode materials, opening up a possible approach for developing wide-voltage aqueous SCs.
\end{abstract}

Keywords: hollow nanosphere, integrated electrode, supercapacitor, voltage window, energy density

\section{INTRODUCTION}

Representing a promising renewable energy technology, supercapacitors (SCs) have attracted continuous attention owing to their high-power density, cycling durability, and safety [1-3]. Unfortunately, the practical application of SCs has been limited by their low energy density [4-6]. According to the equation $E=0.5 C V^{2}$ (where $E, C$, and $V$ are the energy density, specific capacitance, and voltage window of the devices, respectively), numerous materials have been developed to increase the specific capacitance, with the aim of improving the energy density [7-9]. In contrast to the specific capacitance, the energy density is proportional to the square of the cell voltage. Therefore, increasing the voltage window of the devices is an extremely effective strategy to enhance their energy density $[10,11]$.

Due to the low decomposition voltage of water $(\sim 1.23 \mathrm{~V})$, organic electrolytes are usually used in SCs to increase the voltage window [12-15]. However, compared with organic electrolytes with flammability and low conductivity properties, aqueous electrolytes with a sufficiently high working voltage window are considered to be an appropriate alternative to organic electrolytes [16]. In recent years, numerous materials have been designed to increase the voltage window of aqueous electrolyte SCs (AESCs), such as polyanionic molybdenophosphate [17], heteroatom-doped carbon [9], and alkali cation-doped manganese oxide [18-20]. These materials can effectively inhibit the occurrence of the hydrogen evolution reaction or oxygen evolution reaction in a charging-discharging process [21]. However, since the above materials do not possess high positive and negative voltage windows at the same time, it is necessary to adopt two different electrode

\footnotetext{
${ }^{1}$ Institute of Polymers and Energy Chemistry (IPEC), College of Chemistry, Nanchang University, Nanchang 330031, China

${ }^{2}$ School of Materials Science and Engineering, Nanchang University, Nanchang 330031, China

${ }^{3}$ Institute of Advanced Scientific Research (iASR), Jiangxi Normal University, Nanchang 330022, China

† These authors contributed equally to this paper.

* Corresponding authors (emails: kai.yuan@ncu.edu.cn (Yuan K); ywchen@ncu.edu.cn (Chen Y))
} 
materials for the asymmetric design. Thus, researchers usually design and adjust two electrodes with the highest matching degree to prepare optimal AESCs. Nevertheless, the specific capacitance and voltage window of the negative electrode are difficult to match to those of the positive electrode, which has a negative effect on the SCs' energy density. Therefore, it is urgently needed to explore alternative materials with high-voltage windows, which can meet the requirements of both positive and negative electrodes.

$\mathrm{V}_{2} \mathrm{O}_{3}$ has rarely been employed in commercial SCs because of its low capacitance and poor cycling stability. One of the most feasible methods to enhance the electrochemical performance of $\mathrm{V}_{2} \mathrm{O}_{3}$ consists of incorporating highly electrically conductive carbonaceous materials. Indeed, carbonaceous materials (such as porous carbon and graphene) can act as an elastic buffer layer to relieve the structural strain in $\mathrm{V}_{2} \mathrm{O}_{3}$ during cycling, thus further improving the conductivity of the material [22-30]. In addition, the design of hollow structures is a popular way to optimize the rate capabilities of pseudocapacitance electrode materials without sacrificing their power density. Hollow structures can indeed provide an abundance of available electroactive sites, thereby shortening the ion transport pathways [31]. In particular, hollow materials with a hierarchical structure can further enlarge the electroactive surface area and energy density of electrode materials. Therefore, using materials composed of carbonaceous materials and $\mathrm{V}_{2} \mathrm{O}_{3}$ as integrated electrodes represents an excellent approach to improve the electrochemical performance of SCs.

Here, we present a simple glucose-assisted hydrothermal method with low-temperature annealing for the preparation of a hollow $\mathrm{V}_{2} \mathrm{O}_{3} /$ carbon nanosphere $(\mathrm{H}$ $\mathrm{V}_{2} \mathrm{O}_{3} / \mathrm{C}$ ) integrated electrode. The deliberately designed composite materials maintain a hollow spherical structure with a diameter of about $750 \mathrm{~nm}$, which can provide high porosity and a large accessible area for the electrochemical reaction. Moreover, the $\mathrm{H}-\mathrm{V}_{2} \mathrm{O}_{3} / \mathrm{C}$ integrated electrode can simultaneously act as both a negative and positive electrode. The as-prepared $\mathrm{H}-\mathrm{V}_{2} \mathrm{O}_{3} / \mathrm{C}-3$ materials show high specific capacitances of 708.6 and $265.1 \mathrm{~F} \mathrm{~g}^{-1}$ at 1 and $100 \mathrm{Ag}^{-1}$, respectively. After 10,000 cycles, the specific capacitance retains $98.39 \%$ of its initial value. Furthermore, the integrated full SC based on $\mathrm{H}-\mathrm{V}_{2} \mathrm{O}_{3} / \mathrm{C}$ as both the positive and negative electrode exhibits improved capacitance and potential window, owing to the multiple charge storage mechanisms. The aqueous SC devices display a wide voltage window of $2.4 \mathrm{~V}$, achieving an ultrahigh energy density of $96.8 \mathrm{~W} \mathrm{~h} \mathrm{~kg}^{-1}$ at a power density of $1204.6 \mathrm{~W} \mathrm{~kg}^{-1}$ with outstanding electrochemical stability.

\section{EXPERIMENTAL SECTION}

Preparation of $\mathrm{H}-\mathrm{V}_{2} \mathrm{O}_{3} / \mathrm{C}, \mathrm{V}_{2} \mathrm{O}_{3}$ and glucose-derived carbon Firstly, $500 \mathrm{mg}$ of glucose was dissolved in a mixture solvent composed of $40 \mathrm{~mL}$ of deionized water and $10 \mathrm{~mL}$ of isopropyl alcohol to obtain a glucose solution. Then, $15,30,60$, and $120 \mathrm{mg}$ of vanadyl acetylacetonate were added to the glucose solution. The above solution was transferred into a $100-\mathrm{mL}$ Teflon-lined autoclave and heated to $170^{\circ} \mathrm{C}$ for $24 \mathrm{~h}$ to form the $\mathrm{V}_{2} \mathrm{O}_{3}$-precursor. The precipitate was collected via centrifugation after cooling down to room temperature. After drying, the $\mathrm{V}_{2} \mathrm{O}_{3}$-precursor powder was annealed in a furnace with a ramping rate of $2^{\circ} \mathrm{C} \mathrm{min}^{-1}$ up to $500^{\circ} \mathrm{C}$ and kept for $1.5 \mathrm{~h}$ under air atmosphere. This procedure yielded $\mathrm{H}-\mathrm{V}_{2} \mathrm{O}_{3} / \mathrm{C}$ samples containing $15,30,60$, and $120 \mathrm{mg}$ of vanadyl acetylacetonate, which were respectively labeled as $\mathrm{H}-\mathrm{V}_{2} \mathrm{O}_{3} /$ $\mathrm{C}-1, \mathrm{H}-\mathrm{V}_{2} \mathrm{O}_{3} / \mathrm{C}-2, \mathrm{H}-\mathrm{V}_{2} \mathrm{O}_{3} / \mathrm{C}-3$, and $\mathrm{H}-\mathrm{V}_{2} \mathrm{O}_{3} / \mathrm{C}-4$. For comparison, $\mathrm{V}_{2} \mathrm{O}_{3}$ and glucose-derived carbon were prepared via the same method, without adding glucose and vanadyl acetylacetonate, respectively.

\section{RESULTS AND DISCUSSION}

The preparation of $\mathrm{H}-\mathrm{V}_{2} \mathrm{O}_{3} / \mathrm{C}$ samples is illustrated in Fig. 1a. The $\mathrm{H}-\mathrm{V}_{2} \mathrm{O}_{3} / \mathrm{C}$ samples were obtained via a simple glucose-assisted hydrothermal method followed by low-temperature air annealing. Glucose was used as the carbon source, and vanadyl acetylacetonate served as the precursor of $\mathrm{V}_{2} \mathrm{O}_{3}$. The morphologies of the obtained materials were examined via field-emission scanning electron microscopy (FESEM). As displayed in Fig. S1, the $\mathrm{V}_{2} \mathrm{O}_{3}$-precursor shows a spherical morphology assembled by nanosheets, with the nanospheres having an average diameter of about $750 \mathrm{~nm}$. After annealing, the $\mathrm{H}-\mathrm{V}_{2} \mathrm{O}_{3} / \mathrm{C}-3$ sample (Fig. 1b) retains the same morphology as the $\mathrm{V}_{2} \mathrm{O}_{3}$-precursor, demonstrating that the structure of the $\mathrm{V}_{2} \mathrm{O}_{3}$-precursor does not collapse after annealing in air. Besides, the morphology is well maintained in a large scale (Fig. S2a). The $\mathrm{H}-\mathrm{V}_{2} \mathrm{O}_{3} / \mathrm{C}-3$ sample was further analyzed via energy dispersive spectrometry (EDS) (Fig. S2b-d). The EDS mappings show that the V, $\mathrm{O}$, and $\mathrm{C}$ elements are evenly distributed throughout the sphere.

The nanostructure of the as-prepared $\mathrm{H}-\mathrm{V}_{2} \mathrm{O}_{3} / \mathrm{C}-3$ sample was further investigated with transmission electron microscopy (TEM) (Fig. 1c and Fig. S3), which confirms the hollow sphere structure of $\mathrm{H}-\mathrm{V}_{2} \mathrm{O}_{3} / \mathrm{C}-3$. The 

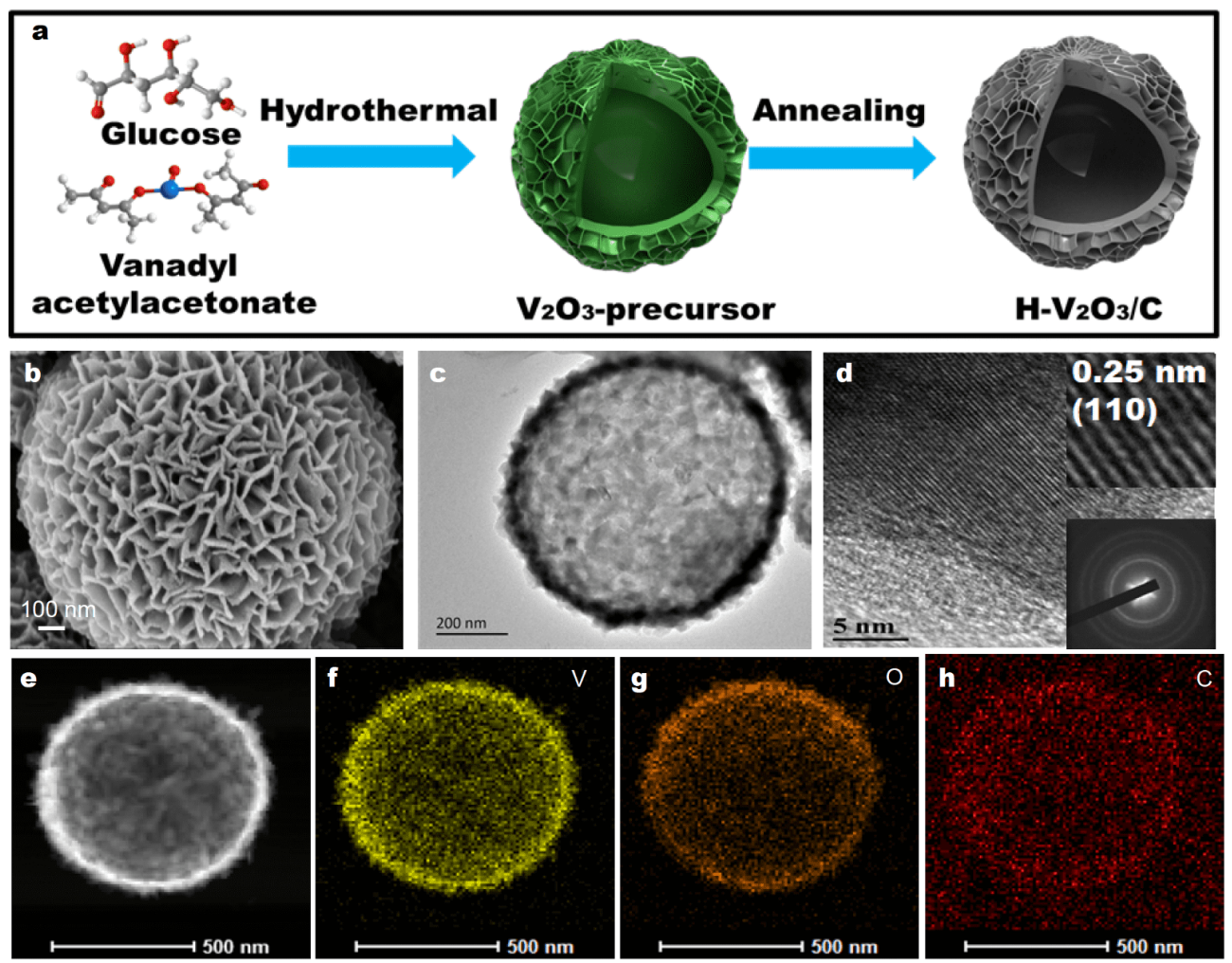

Figure 1 (a) Schematic diagram illustrating the fabrication of $\mathrm{H}_{-} \mathrm{V}_{2} \mathrm{O}_{3} / \mathrm{C}$ samples. (b) FESEM image, and (c) TEM image of sample $\mathrm{H}-\mathrm{V}_{2} \mathrm{O}_{3} / \mathrm{C}-3$. (d) HRTEM and SAED images of sample $\mathrm{H}-\mathrm{V}_{2} \mathrm{O}_{3} / \mathrm{C}-3$. (e-h) The corresponding EDS mappings of $\mathrm{V}, \mathrm{O}$, and $\mathrm{C}$ of the sample $\mathrm{H}-\mathrm{V}_{2} \mathrm{O}_{3} / \mathrm{C}-3$.

high-resolution TEM (HRTEM) images for $\mathrm{H}-\mathrm{V}_{2} \mathrm{O}_{3} / \mathrm{C}-3$ shown in Fig. 1d display a lattice spacing of $0.25 \mathrm{~nm}$, which corresponds to the (110) crystal plane of $\mathrm{V}_{2} \mathrm{O}_{3}$. The selected area electron diffraction (SAED) pattern of the $\mathrm{H}-\mathrm{V}_{2} \mathrm{O}_{3} / \mathrm{C}-3$ sample shows the typical polycrystalline texture of the $\mathrm{V}_{2} \mathrm{O}_{3}$ species, whereby the sequence of distinct rings can be attributed to the (012), (104), (110), and (113) diffraction planes of the crystalline $\mathrm{V}_{2} \mathrm{O}_{3}$ [30]. Furthermore, it can be seen from the EDS mapping that the $\mathrm{V}, \mathrm{O}$, and $\mathrm{C}$ elements are mainly distributed around the shell layer (Fig. 1e-h), which further indicates that the materials have hollow structures. The hollow nanospheres with a rich internal space can maximize the availability of active sites and shorten the electron/ion diffusion path [31]. The $\mathrm{N}_{2}$ adsorption-desorption isotherms and poresize distributions of the $\mathrm{V}_{2} \mathrm{O}_{3}$-precursor and $\mathrm{H}-\mathrm{V}_{2} \mathrm{O}_{3} / \mathrm{C}-3$ sample were next characterized to evaluate the annealing effects on the surface area. Each sample shows a typical $\mathrm{IV}$ isotherm with a $\mathrm{H}_{3}$-type hysteresis loop (Fig. S4a). The pore-size distribution curves based on the density functional theory method in Fig. S4b present a pore-size distribution centered at $2.6 \mathrm{~nm}$, proving the existence of a myriad of mesopores. The total pore volume of the sample $\mathrm{H}-\mathrm{V}_{2} \mathrm{O}_{3} / \mathrm{C}-3\left(0.367 \mathrm{~cm}^{3} \mathrm{~g}^{-1}\right)$ is larger than that of the $\mathrm{V}_{2} \mathrm{O}_{3}$-precursor $\left(0.161 \mathrm{~cm}^{3} \mathrm{~g}^{-1}\right)$, proving that more mesopores were created due to the thermal decomposition of glucose [32]. The $\mathrm{H}-\mathrm{V}_{2} \mathrm{O}_{3} / \mathrm{C}-3$ sample exhibits an excellent Brunauer-Emmett-Teller surface area of $236 \mathrm{~m}^{2} \mathrm{~g}^{-1}$, which is considerably higher than that of the $\mathrm{V}_{2} \mathrm{O}_{3}$-precursor $\left(107 \mathrm{~m}^{2} \mathrm{~g}^{-1}\right)$. The porous structure of $\mathrm{H}$ $\mathrm{V}_{2} \mathrm{O}_{3} / \mathrm{C}-3$ with the increased specific surface area is beneficial to the rapid diffusion of electron/ions [33].

The phases of the materials were evaluated via X-ray diffraction (XRD), as shown in Fig. 2a. The diffraction peaks located at $24.3^{\circ}, 32.9^{\circ}, 36.2^{\circ}, 41.2^{\circ}$, and $53.9^{\circ}$ are assigned to the (012), (104), (110), (113), and (116) phases of rhombohedral $\mathrm{V}_{2} \mathrm{O}_{3}$ (JCPFS, No. 34-0187). The diffraction peaks for carbon in the $\mathrm{H}-\mathrm{V}_{2} \mathrm{O}_{3} / \mathrm{C}-3$ sample are hidden by the intense diffraction peaks of $\mathrm{V}_{2} \mathrm{O}_{3}$. The corresponding compositions and valence states were further examined via X-ray photoelectron spectroscopy (XPS). The presence of the $\mathrm{C}, \mathrm{V}$, and $\mathrm{O}$ elements in $\mathrm{H}$ $\mathrm{V}_{2} \mathrm{O}_{3} / \mathrm{C}-3$ is supported by the XPS survey spectrum, as shown in Fig. S5. From the high-resolution XPS diagram of V 2p (Fig. 2b), the V 2p spectrum can be deconvoluted into two spin-orbit doublets. The peaks located at 517.0 

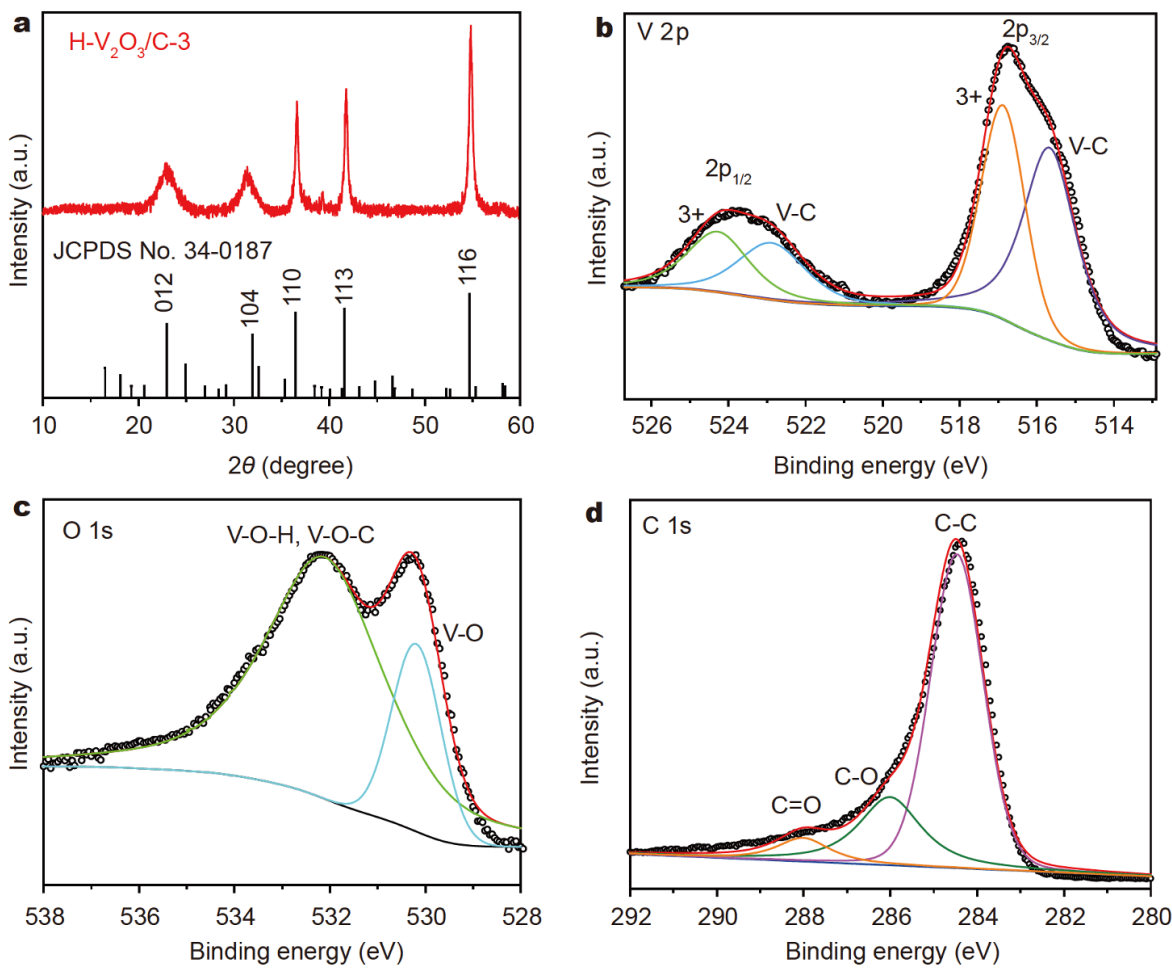

Figure 2 (a) XRD patterns for sample $\mathrm{H}-\mathrm{V}_{2} \mathrm{O}_{3} / \mathrm{C}-3$. High-resolution XPS spectra of (b) V 2p, (c) O 1s, and (d) C 1 s.

and $524.5 \mathrm{eV}$ are ascribed to $\mathrm{V}^{3+}$, whereas the binding energies at 515.6 and $522.9 \mathrm{eV}$ are ascribed to the $\mathrm{V}-\mathrm{C}$ bond [34]. Similarly, in the high-resolution O 1s XPS diagram, the peak with a low binding energy of $530.2 \mathrm{eV}$ is attributed to the $\mathrm{V}-\mathrm{O}$ bond energy at the interface, whereas the binding energy at $532.1 \mathrm{eV}$ corresponds to the hydrated conjugates, such as $\mathrm{V}-\mathrm{O}-\mathrm{H}$ and $\mathrm{V}-\mathrm{O}-\mathrm{C}$ (Fig. 2c) [35]. The deconvoluted C 1s XPS spectrum (Fig. 2d) includes three peaks, corresponding to $\mathrm{C}-\mathrm{C}$ $(284.3 \mathrm{eV}), \mathrm{C}-\mathrm{O}(286.0 \mathrm{eV})$, and $\mathrm{C}=\mathrm{O}(288.2 \mathrm{eV})$, respectively [36].

To explore the influence of the concentration of vanadyl acetylacetonate on the electrochemical performance of the electrode materials, different samples were prepared by adjusting the reaction concentration of vanadyl acetylacetonate. The electrochemical performances of $\mathrm{H}$ $\mathrm{V}_{2} \mathrm{O}_{3} / \mathrm{C}-1, \mathrm{H}-\mathrm{V}_{2} \mathrm{O}_{3} / \mathrm{C}-2, \mathrm{H}-\mathrm{V}_{2} \mathrm{O}_{3} / \mathrm{C}-3$, and $\mathrm{H}-\mathrm{V}_{2} \mathrm{O}_{3} / \mathrm{C}-4$ were tested in a three-electrode system. Cyclic voltammetry $(\mathrm{CV})$ curves under various potential windows at $50 \mathrm{mV} \mathrm{s}^{-1}$ were collected in order to determine the maximum available voltage window of the samples. As demonstrated in Fig. 3a, when the positive voltage window exceeds $1.3 \mathrm{~V}$, the $\mathrm{CV}$ curve is polarized. In the voltage range of $-1.1-1.3 \mathrm{~V}$, the $\mathrm{CV}$ curve of the material remains a stable voltage window. At a scanning rate of
$50 \mathrm{mV} \mathrm{s}^{-1}$ and in a potential window between -1.1 and $1.3 \mathrm{~V}$, the integrated $\mathrm{CV}$ area of $\mathrm{H}-\mathrm{V}_{2} \mathrm{O}_{3} / \mathrm{C}-3$ is clearly larger than those of $\mathrm{H}-\mathrm{V}_{2} \mathrm{O}_{3} / \mathrm{C}-1, \mathrm{H}-\mathrm{V}_{2} \mathrm{O}_{3} / \mathrm{C}-2$, and $\mathrm{H}$ $\mathrm{V}_{2} \mathrm{O}_{3} / \mathrm{C}-4$. This indicates that sample $\mathrm{H}-\mathrm{V}_{2} \mathrm{O}_{3} / \mathrm{C}-3$ has a larger specific capacitance (Fig. S6a). Galvanostatic charge-discharge (GCD) measurements were also performed to evaluate the performance of the electrode materials. Under a current density of $1 \mathrm{~A} \mathrm{~g}^{-1}$, the GCD curves of the four samples show that the $\mathrm{H}-\mathrm{V}_{2} \mathrm{O}_{3} / \mathrm{C}-3$ electrode material has a longer discharge time (1700.7 s) and a lower $I R$ drop $(0.009 \mathrm{~V})$. Furthermore, these curves show that the $\mathrm{H}-\mathrm{V}_{2} \mathrm{O}_{3} / \mathrm{C}-3$ material has a high capacitance value and excellent conductivity (Fig. S6b). The influence of the carbon content on the charge (ions and electrons) transport kinetics was characterized via electrochemical impedance spectra (EIS). From the EIS graphs measured under the same conditions, it can be seen that the $\mathrm{H}-\mathrm{V}_{2} \mathrm{O}_{3} / \mathrm{C}-3$ electrode material has a smaller arc radius and a higher slope compared with the others. This proves that the $\mathrm{H}-\mathrm{V}_{2} \mathrm{O}_{3} / \mathrm{C}-3$ electrode material has a smaller resistance and higher conductivity (Fig. S6c).

The specific capacitances of all samples at different current densities were calculated by integrating the corresponding GCD curves, as displayed in Fig. 3b. It can be seen that the specific capacitance of the electrode mate- 

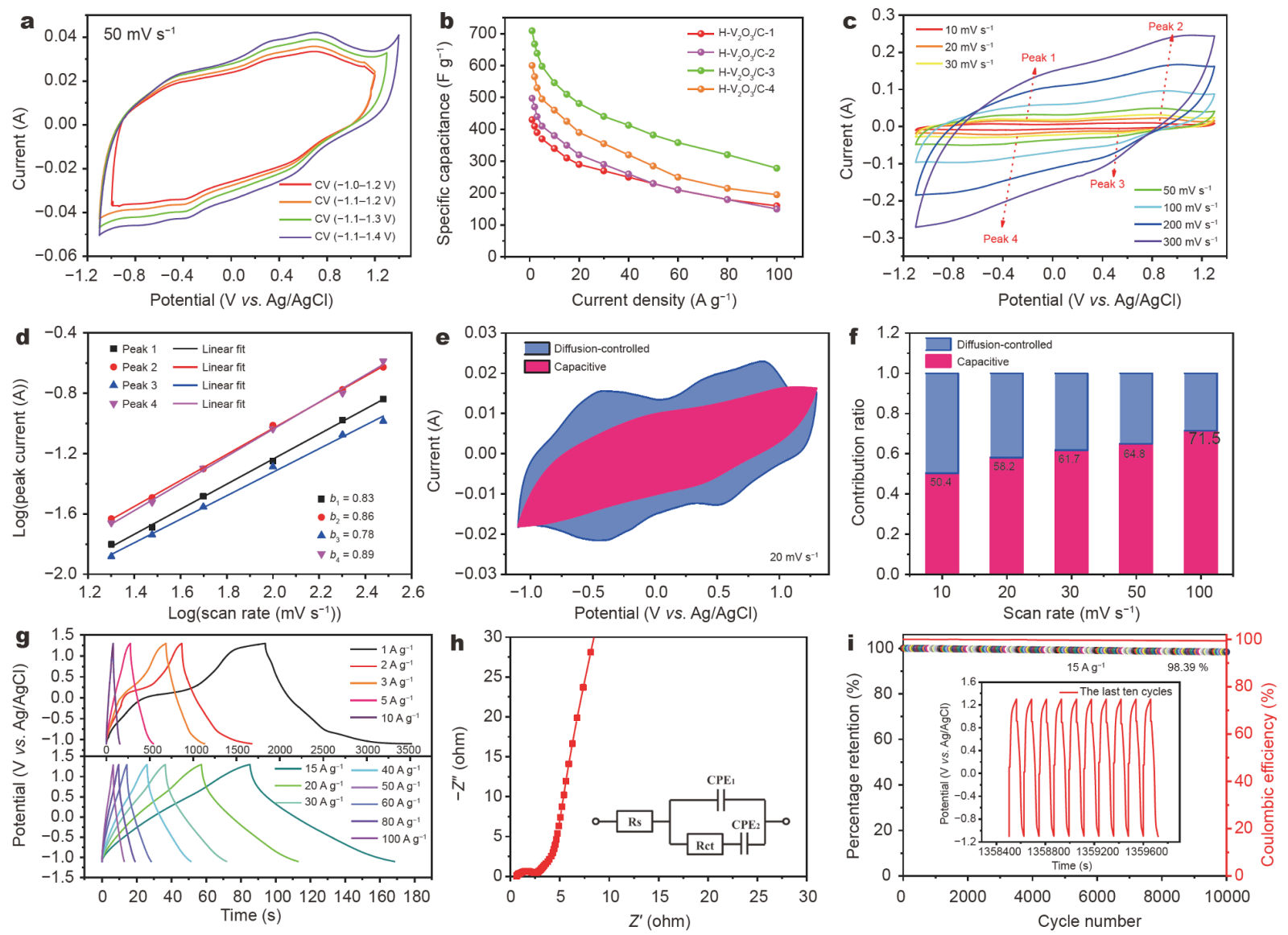

Figure 3 (a) $\mathrm{CV}$ curves of $\mathrm{H}-\mathrm{V}_{2} \mathrm{O}_{3} / \mathrm{C}-3$ under various potential windows. (b) Specific capacitance of $\mathrm{H}-\mathrm{V}_{2} \mathrm{O}_{3} / \mathrm{C}$ for different current densities. (c, d) CV curves at 10-300 mV s${ }^{-1}$ scan rates and the calculated $b$ values for $\mathrm{H}_{-} \mathrm{V}_{2} \mathrm{O}_{3} / \mathrm{C}-3$. (e) $\mathrm{CV}$ curve with capacitive and diffusion-controlled capacitances indicated at a scan rate of $20 \mathrm{mV} \mathrm{s}^{-1}$. (f) Contribution ratio of the capacitive and diffusion-controlled capacitances at different scan rates. (g) GCD curves of $\mathrm{H}-\mathrm{V}_{2} \mathrm{O}_{3} / \mathrm{C}-3$ at various current densities. (h) EIS curve of $\mathrm{H}-\mathrm{V}_{2} \mathrm{O}_{3} / \mathrm{C}-3$ (inset: the corresponding equivalent circuit diagram). (i) Capacitance retention and coulombic retention as a function of the cycle number at a current density of $15 \mathrm{Ag} \mathrm{g}^{-1}$ for $\mathrm{H}-\mathrm{V}_{2} \mathrm{O}_{3} / \mathrm{C}-3$ (inset: the corresponding GCD curves for the last 10 cycles).

rials increases first and then decreases, with $\mathrm{H}-\mathrm{V}_{2} \mathrm{O}_{3} / \mathrm{C}-3$ exhibiting the highest specific capacitance. This can be attributed to the fact that increasing the concentration of vanadyl acetylacetonate can lead to an increase in the amount of $\mathrm{V}_{2} \mathrm{O}_{3}$ in the product. At the beginning, the carbon material and $\mathrm{V}_{2} \mathrm{O}_{3}$ material cooperate to increase the overall conductivity and rate performance, and an adequate proportion of $\mathrm{V}_{2} \mathrm{O}_{3}$ to carbon can result in a favorable synergistic effect to improve the electrochemical performance. However, as the concentration increases further $\left(\mathrm{H}-\mathrm{V}_{2} \mathrm{O}_{3} / \mathrm{C}-4\right)$, the excess $\mathrm{V}_{2} \mathrm{O}_{3}$ limits the advantages of carbon, leading to a lower specific capacitance and rate performance. For comparison, the electrochemical performance of pure $\mathrm{V}_{2} \mathrm{O}_{3}$ is shown in Fig. S7. The specific capacitance and voltage window of pure $\mathrm{V}_{2} \mathrm{O}_{3}$ are lower than that of the integrated $\mathrm{H}-\mathrm{V}_{2} \mathrm{O}_{3} / \mathrm{C}$ electrode, illustrating the advantages of $\mathrm{H}-\mathrm{V}_{2} \mathrm{O}_{3} / \mathrm{C}$ in the electrochemical performance.

The CV curves demonstrate that the $\mathrm{H}-\mathrm{V}_{2} \mathrm{O}_{3} / \mathrm{C}-3$ sample shows an outstanding capacitive behavior at 10 $300 \mathrm{mV} \mathrm{s}^{-1}$ (Fig. 3c). It can be seen that the CV curves do not change significantly as the current density increases, indicating an excellent rate capability for the $\mathrm{H}-\mathrm{V}_{2} \mathrm{O}_{3} / \mathrm{C}-3$ electrode. The relationship between the peak current $(i)$ and scan rate $(v)$ follows the empirical formula: $i=a v^{b}$,

where $a$ and $b$ are constants. When $b=0.5$, the electrochemical process is fully diffusion-controlled, whereas $b=$ 1 indicates an ideal capacitive process [37]. The $b$ value represents the slope of the $\log (i)$ versus $\log (v)$ curve (Fig. 3d); the $b$ values of the four peaks for the $\mathrm{H}-\mathrm{V}_{2} \mathrm{O}_{3} / \mathrm{C}$ 3 sample were changed to be $0.83,0.86,0.78$, and 0.89 , respectively. To analyze the total contribution of sample $\mathrm{H}-\mathrm{V}_{2} \mathrm{O}_{3} / \mathrm{C}-3$ at a certain scan rate, the fraction of the 
diffusion-controlled $\left(k_{1} v^{1 / 2}\right)$ and capacitive $\left(k_{2} v\right)$ current must follow the empirical formula: $i=k_{1} v^{1 / 2}+k_{2} v$.

The values of $k_{1}$ and $k_{2}$ correspond to the slope and intercept, respectively, of the $i(V) / v^{1 / 2}$ versus $v^{1 / 2}$ curve at a fixed potential. The contribution rates of the diffusioncontrolled and capacitive capacitances at $10-100 \mathrm{mV} \mathrm{s}^{-1}$ scan rates are presented in Fig. 3e and Fig. S8. The diffusion-controlled and capacitive contributions to the total stored charge of the $\mathrm{H}-\mathrm{V}_{2} \mathrm{O}_{3} / \mathrm{C}-3$ sample at different scan rates are displayed in Fig. 3f. When the sweep speed is $10 \mathrm{mV} \mathrm{s}^{-1}$, the capacitive contribution is $50.4 \%$ of the total charge storage, and the value gradually increases to $71.5 \%$ as the sweep speed increases to $100 \mathrm{mV} \mathrm{s}^{-1}$, leading to a decrease in the total capacitance at high scan rates. These results indicate that the occurrence of diffusioncontrolled processes during the charging-discharging process at low scan speeds endows $\mathrm{H}-\mathrm{V}_{2} \mathrm{O}_{3} / \mathrm{C}-3$ with a high capacitance. In contrast, the electrolyte ions cannot fully diffuse at high sweep speeds, resulting in the capacitance decreasing.

The GCD measurements of $\mathrm{H}-\mathrm{V}_{2} \mathrm{O}_{3} / \mathrm{C}-3$ were implemented in the range of $-1.1-1.3 \mathrm{~V}$ (Fig. $3 \mathrm{~g}$ ). By calculating the GCD, the specific capacitances of $\mathrm{H}-\mathrm{V}_{2} \mathrm{O}_{3} / \mathrm{C}$ 3 were found to be $708.6,667.2,638.4,597.6,546,510$, $481.2,452.5,429.7,358.1,310.4$, and $265.1 \mathrm{~F} \mathrm{~g}^{-1}$ at $1,2,3$, $5,10,15,20,30,40,60,80$, and $100 \mathrm{Ag}^{-1}$, respectively. It can be seen that, as the current density rises from 1 to $100 \mathrm{~A} \mathrm{~g}^{-1}$, the specific capacitance of the $\mathrm{H}-\mathrm{V}_{2} \mathrm{O}_{3} / \mathrm{C}-3$ electrode remains $37.4 \%$ of the initial value (Fig. S8). The capacitance degradation can be attributed to the insufficient diffusion of the electrolyte ions at high current densities. The EIS diagram of the $\mathrm{H}-\mathrm{V}_{2} \mathrm{O}_{3} / \mathrm{C}-3$ electrode and the corresponding equivalent circuit diagram are shown in Fig. 3h. The intersection between the curve and the abscissa in the low frequency region represents the system resistance $\left(R_{\mathrm{s}}\right)$, which includes mainly the contact resistance of $\mathrm{H}-\mathrm{V}_{2} \mathrm{O}_{3} / \mathrm{C}-3$ and the nickel foam substrate, the resistance of the nickel foam, and the resistance of the $\mathrm{Na}_{2} \mathrm{SO}_{4}$ electrolyte. The diameter of the semicircle in the high-frequency region corresponds to the charge transfer resistance $\left(R_{\mathrm{ct}}\right)$. Through analysis, the $R_{\mathrm{s}}$ and $R_{\mathrm{ct}}$ values of the $\mathrm{H}-\mathrm{V}_{2} \mathrm{O}_{3} / \mathrm{C}-3$ electrode were found to be 0.6 and $2.0 \Omega$, respectively, which indicates that the $\mathrm{H}-\mathrm{V}_{2} \mathrm{O}_{3} / \mathrm{C}-3$ electrode has a fast electron and ion transmission rate.

Furthermore, the cycling performance of the $\mathrm{H}-\mathrm{V}_{2} \mathrm{O}_{3} /$ C-3 electrode measured via GCD at $15 \mathrm{~A} \mathrm{~g}^{-1}$ is shown in Fig. 3i for 10,000 cycles. The capacitance retains $98.39 \%$ of the original capacitance after 10,000 cycles, and the coulombic efficiency is $99.6 \%$, indicating an excellent cycling performance. The inset of Fig. 3i shows the GCD profile of the last 10 cycles. The shape of the curve remains good, which shows that the material structure changes are limited even after 10,000 cycles. Moreover, this shows that the electrode material has good stability and utilization rate. The excellent cycling stability can be attributed to the $\mathrm{H}-\mathrm{V}_{2} \mathrm{O}_{3} / \mathrm{C}-3$ electrode having the following advantages: (1) carbon endows the material with an excellent conductivity and highly efficient electron transfer rate; (2) the hollow structure enables the material to have a larger specific surface area, thus permitting a larger amount of active materials to be in full contact with the electrolyte. In this way, a rapid Faraday reaction can occur [38].

To further evaluate $\mathrm{H}-\mathrm{V}_{2} \mathrm{O}_{3} / \mathrm{C}-3$ for practical applications, a symmetrical coin-type integrated full SC device was assembled using the $\mathrm{H}-\mathrm{V}_{2} \mathrm{O}_{3} / \mathrm{C}-3$ material as both the cathode and anode. In order to determine the maximum stable operating voltage range of the integrated full SC, $\mathrm{CV}$ curves under various potential windows of 0-2.0, 2.1, $2.2,2.3,2.4$, and $2.5 \mathrm{~V}$ were recorded. The test curves show that the device can reach a maximum stable window up to $2.4 \mathrm{~V}$ (Fig. $4 \mathrm{a}$ ). The CV curves demonstrate that the integrated SCs exhibit a superior capacitive behavior in the range of $10-500 \mathrm{mV} \mathrm{s}^{-1}$ under $0-2.4 \mathrm{~V}$ (Fig. 4b). The shape of the CV curve is wildly deformed upon increasing the current density, which is due to the hollow spherical structure enabling the rapid diffusion of ions/electrons. The GCD curves of the device at different current densities are shown in Fig. 4c. The integrated full SC device possesses a specific capacitance of $121 \mathrm{~F} \mathrm{~g}^{-1}$ at a current density of $1 \mathrm{Ag}^{-1}$, as calculated using the discharge curves. As the current density increases to $2,3,5,10,20$, 30 , and $40 \mathrm{~A} \mathrm{~g}^{-1}$, the specific capacitance remains $88.4 \%$, $79.3 \%, 67.7 \%, 55.3 \%, 44.6 \%, 36.4 \%$, and $28.1 \%$, respectively, of the original specific capacitance (Fig. S9). The EIS diagram of the integrated SC and the corresponding equivalent circuit diagram are shown in Fig. $4 \mathrm{~d}$. The $R_{\mathrm{s}}$ and $R_{\mathrm{ct}}$ values of the integrated SC were measured to be 1.2 and $4.8 \Omega$, respectively, leading to a higher reactivity and faster reaction kinetics. Hence, these advantages endow the $\mathrm{H}-\mathrm{V}_{2} \mathrm{O}_{3} / \mathrm{C}-3$ sample with superior electrochemical performance.

Fig. 4e shows the Ragone plots of the energy density and power density for the integrated SC device. The highest energy density obtained with the coin-type SC device is $96.8 \mathrm{~W} \mathrm{~h} \mathrm{~kg}^{-1}$ at a power density of $1204.6 \mathrm{~W} \mathrm{~kg}^{-1}$. In addition, the device still delivers an energy density of $27.2 \mathrm{~W} \mathrm{~h} \mathrm{~kg}^{-1}$ at a high power density of $11,826.1 \mathrm{~W} \mathrm{~kg}^{-1}$. This performance is superior to that of 

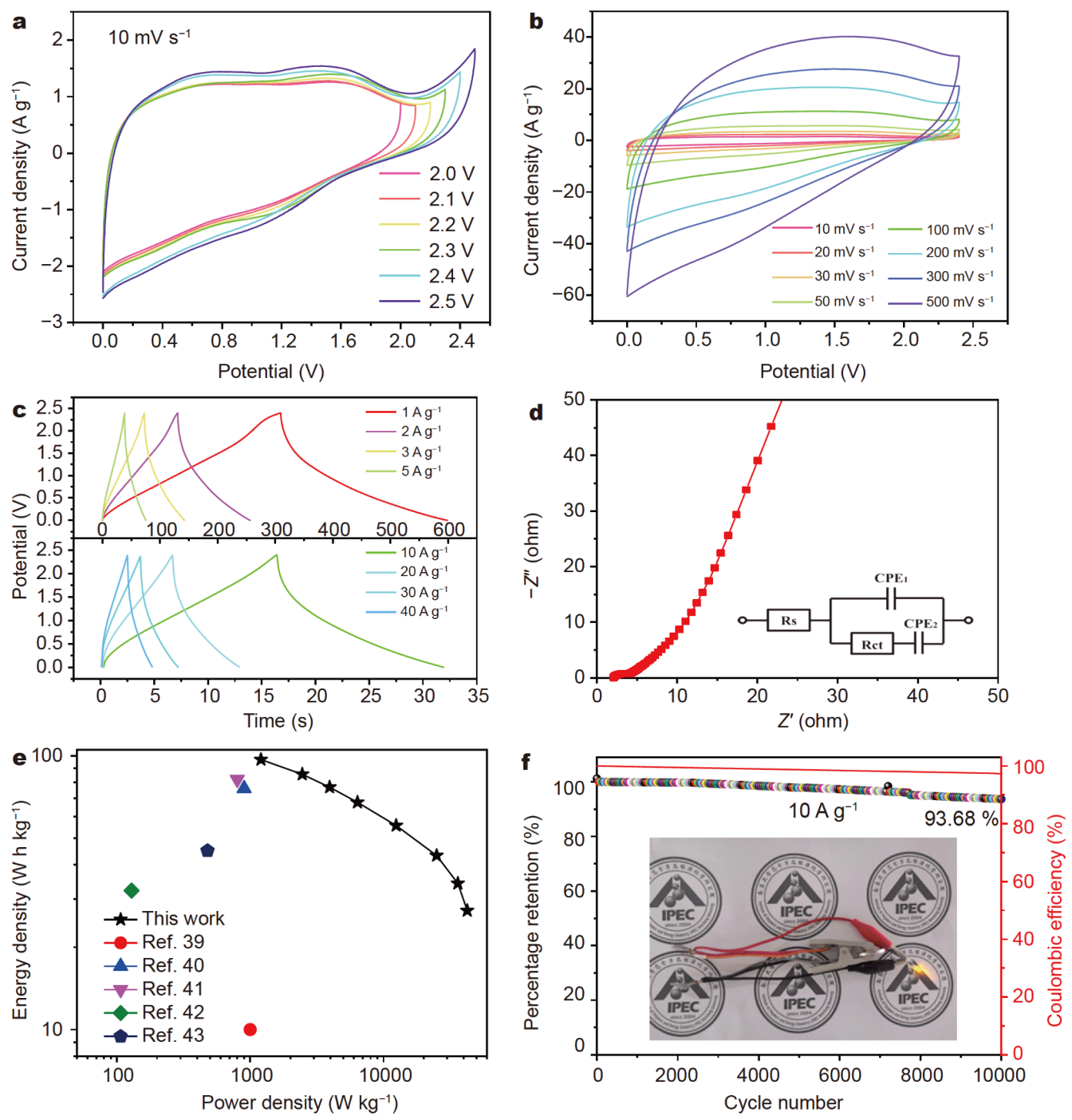

Figure 4 (a) CV curves of the integrated full SC under various potential windows at $10 \mathrm{mV} \mathrm{s}^{-1}$. (b) $\mathrm{CV}$ curves of the integrated SC at different scan rates. (c) GCD curves of the integrated SC at different current densities. (d) EIS curve of the integrated full SC (inset: the corresponding equivalent circuit diagram). (e) Ragone plots of the energy density and power density for the integrated SC compared with literature results. (f) Capacitance retention and coulombic retention for the integrated full SC as a function of the cycle number at a current density of $10 \mathrm{~A} \mathrm{~g}^{-1}$ (inset: photographic image of an LED operated by one integrated SC device).

the vanadium-based devices reported in the literature, such as the $\mathrm{V}_{2} \mathrm{O}_{3} / \mathrm{VO}_{x}$ core-shell composite symmetrical device (when the power density is $1000 \mathrm{~W} \mathrm{~kg}^{-1}$, the energy density is $10 \mathrm{~W} \mathrm{~h} \mathrm{~kg}^{-1}$ ) [39], $\mathrm{rGO} / \mathrm{V}_{2} \mathrm{O}_{5} \mathrm{NS} / / \mathrm{rGO}$ asymmetrical device (when the power density is $900 \mathrm{~W} \mathrm{~kg}^{-1}$, the energy density is $75.9 \mathrm{~W} \mathrm{~h} \mathrm{~kg}^{-1}$ ) [40], $\mathrm{V}_{2} \mathrm{O}_{5}$-PPy symmetrical device (when the power density is $800 \mathrm{~W} \mathrm{~kg}^{-1}$, the energy density is $82 \mathrm{~W} \mathrm{~h} \mathrm{~kg}^{-1}$ ) [41], $\mathrm{V}_{2} \mathrm{O}_{5}$ $\mathrm{NFs} / / \mathrm{Fe}_{2} \mathrm{O}_{3} \mathrm{NFs}$ asymmetrical device (when the power density is $128.7 \mathrm{~W} \mathrm{~kg}^{-1}$, the energy density is $32.2 \mathrm{~W} \mathrm{~h} \mathrm{~kg}^{-1}$ ) [42], and $\mathrm{MnO}_{2}$ /graphene//VOS@C (when the power density is $478.5 \mathrm{~W} \mathrm{~kg}^{-1}$, the energy density is $45 \mathrm{~W} \mathrm{~h} \mathrm{~kg}^{-1}$ ) [43]. To evaluate the cyclic performance of the SC, the capacitance retention was measured and the corresponding results are shown in Fig. $4 \mathrm{f}$. After 10,000 cycles, the capacitance retention rate and coulombic efficiency of the coin-type device were found to be $93.68 \%$ and $97.51 \%$, respectively, indicating that the $\mathrm{H}-\mathrm{V}_{2} \mathrm{O}_{3} / \mathrm{C}-3$ integrated electrode has good redox reversibility. Moreover, a single coin-type SC could light up a yellow LED light, demonstrating its potential for practical applications.

To further explore the reason behind the high electrochemical performance of $\mathrm{H}-\mathrm{V}_{2} \mathrm{O}_{3} / \mathrm{C}$ integrated elec- 
trodes, the underlying mechanisms for the energy storage in the as-prepared $\mathrm{H}-\mathrm{V}_{2} \mathrm{O}_{3} / \mathrm{C}-3$ sample were investigated. Integrated SCs are beneficial to the electrochemical performances of half SCs and full SCs, which are illustrated by the simulation diagrams in Fig. 5. For a single integrated electrode, it is feasible for it to act as both positive and negative electrodes (Fig. 5a). The capacitance and voltage window of the SC device assembled by the integrated electrodes are much larger than those of the traditional symmetrical SCs or asymmetric SCs (Fig. 5b, c). The experimental results could confirm these observations. As shown in the CV curves for the threeelectrode system (Fig. 5d), the glucose-derived carbon and $\mathrm{V}_{2} \mathrm{O}_{3}$ electrodes are polarized below $-1.0 \mathrm{~V}$ and above $1.0 \mathrm{~V}$. In addition, the $\mathrm{CV}$ curves confirm that the integrated $\mathrm{H}-\mathrm{V}_{2} \mathrm{O}_{3} / \mathrm{C}-3$ electrode can work both in the positive and negative voltage window and can deliver a higher capacitance than the single carbon and $\mathrm{V}_{2} \mathrm{O}_{3}$ electrodes. In contrast to other non-integrated full SCs (Fig. 5e, f), the assembled $\mathrm{H}-\mathrm{V}_{2} \mathrm{O}_{3} / \mathrm{C}-3 / / \mathrm{H}-\mathrm{V}_{2} \mathrm{O}_{3} / \mathrm{C}-3$ full
SC delivers higher capacitance and voltage window. The advantages of the integrated $\mathrm{H}-\mathrm{V}_{2} \mathrm{O}_{3} / \mathrm{C}-3 / / \mathrm{H}-\mathrm{V}_{2} \mathrm{O}_{3} / \mathrm{C}-3$ full SC in the specific capacitance and voltage window are due to the fact that it functions based on three types of traditional SCs: a $\mathrm{V}_{2} \mathrm{O}_{3} / / \mathrm{V}_{2} \mathrm{O}_{3}$ symmetric SC, a carbon// carbon symmetric $\mathrm{SC}$, and a $\mathrm{V}_{2} \mathrm{O}_{3} / /$ Carbon asymmetric SC [44]. To conclude, compared with the traditional full $\mathrm{SC}$, the integrated full SC can achieve a threefold charge storage process, thus obtaining a higher capacitance and wider voltage window (Fig. 5g).

\section{CONCLUSIONS}

In summary, the $\mathrm{H}-\mathrm{V}_{2} \mathrm{O}_{3} / \mathrm{C}$ integrated electrode was successfully prepared via a simple glucose-assisted hydrothermal method followed by low-temperature annealing in air. The as-prepared $\mathrm{H}-\mathrm{V}_{2} \mathrm{O}_{3} / \mathrm{C}$ integrated electrode exhibits a hollow nanosphere structure that can provide a myriad of active sites and shorten the electron/ ion diffusion distance. Moreover, the $\mathrm{H}-\mathrm{V}_{2} \mathrm{O}_{3} / \mathrm{C}$ integrated electrode can simultaneously act as both negative
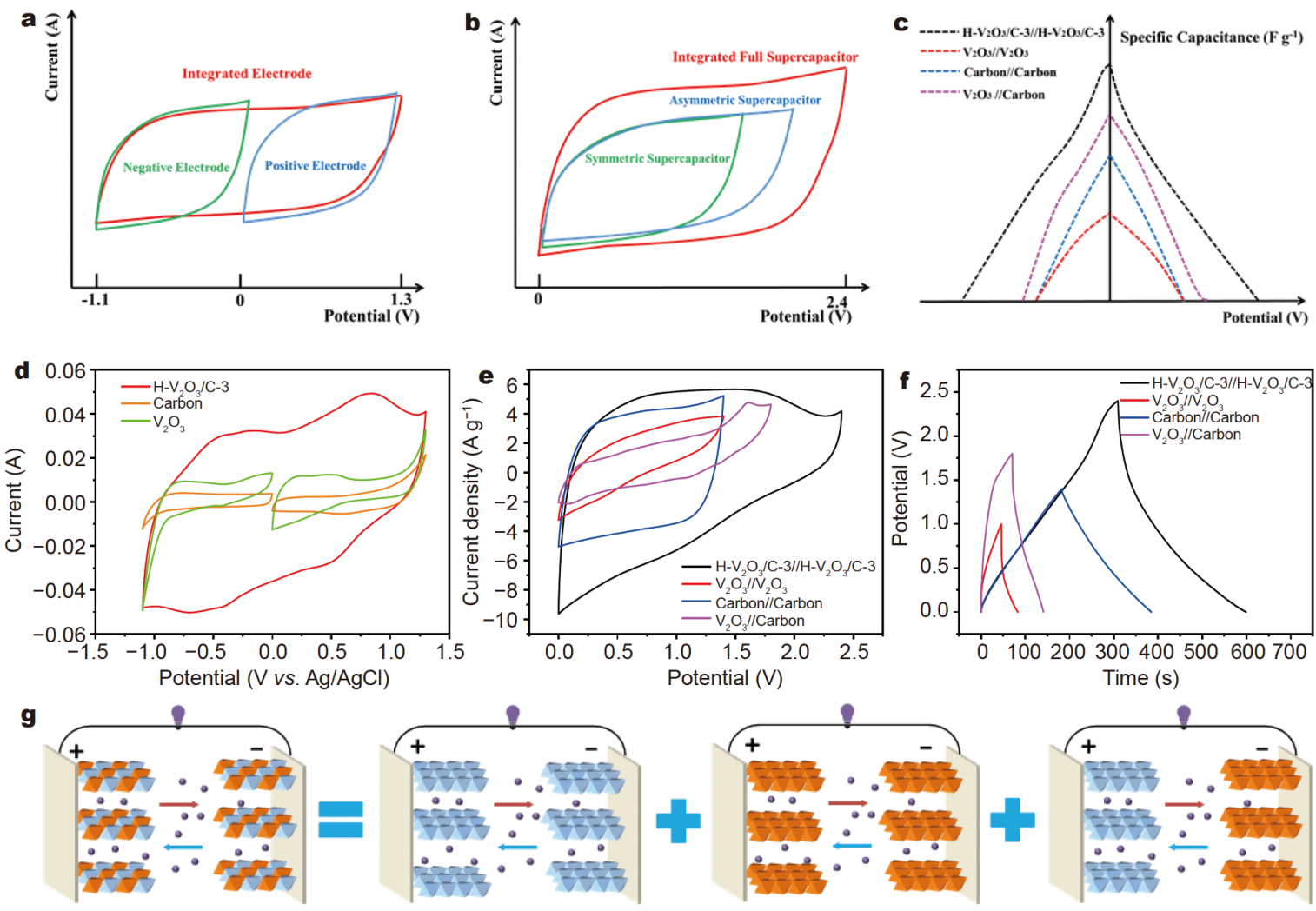

Carbon//Carbon

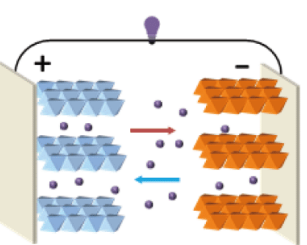

$\mathrm{V}_{2} \mathrm{O}_{3} / \mathrm{N}_{2} \mathrm{O}_{3}$

$\mathrm{V}_{2} \mathrm{O}_{3} / /$ Carbon

Figure 5 Simulation diagram of (a) CV for positive, negative, and integrated electrodes. (b) CV for symmetric, asymmetric, and integrated full SC. (c) Relationship between the potential and specific capacitance. (d) CV curves of single $\mathrm{V}_{2} \mathrm{O}_{3}$, carbon, and $\mathrm{H}-\mathrm{V}_{2} \mathrm{O}_{3} / \mathrm{C}-3$ electrodes. (e) CV curves and (f) GCD curves for symmetric, asymmetric, and integrated full SC at a current density of $1 \mathrm{~A} \mathrm{~g}^{-1}$. (g) Simulation diagram of the integrated full SC $\mathrm{H}$ $\mathrm{V}_{2} \mathrm{O}_{3} / \mathrm{C}-3 / / \mathrm{H}-\mathrm{V}_{2} \mathrm{O}_{3} / \mathrm{C}-3$ compared with the traditional $\mathrm{V}_{2} \mathrm{O}_{3} / / \mathrm{V}_{2} \mathrm{O}_{3}$ symmetric SC, carbon//carbon symmetric SC, and $\mathrm{V}_{2} \mathrm{O}_{3} / /$ carbon asymmetric SC. 
and positive electrodes. Thus, the $\mathrm{H}-\mathrm{V}_{2} \mathrm{O}_{3} / \mathrm{C}$ integrated electrode exhibits an excellent specific capacitance of $708.6 \mathrm{~F} \mathrm{~g}^{-1}$ at $1 \mathrm{Ag}^{-1}$ in a wide voltage window of $-1.1-1.3 \mathrm{~V}$, as well as a superior rate capacity. In addition, the $\mathrm{H}-\mathrm{V}_{2} \mathrm{O}_{3} / \mathrm{C}-3 / / \mathrm{H}-\mathrm{V}_{2} \mathrm{O}_{3} / \mathrm{C}-3$ integrated SC device exhibits a wide potential window of $2.4 \mathrm{~V}$ owing to a threefold charge storage process, which includes the traditional symmetric (positive//positive and negative//negative), and asymmetric (positive//negative) full SC mechanisms. The aqueous integrated full SC shows a superior energy density of $96.8 \mathrm{~W} \mathrm{~h} \mathrm{~kg}^{-1}$ at a power density of $1204.6 \mathrm{~W} \mathrm{~kg}^{-1}$. Therefore, this work offers a simple strategy to fabricate an integrated electrode for the development of aqueous SCs with wide voltage applicability and high energy density.

Received 3 November 2020; accepted 6 January 2021; published online 18 March 2021

1 Shao $\mathrm{H}, \mathrm{Wu} \mathrm{YC}$, Lin $\mathrm{Z}$, et al. Nanoporous carbon for electrochemical capacitive energy storage. Chem Soc Rev, 2020, 49: 30053039

2 Zheng M, Xiao X, Li L, et al. Hierarchically nanostructured transition metal oxides for supercapacitors. Sci China Mater, 2017, 61: 185-209

3 Tie D, Huang S, Wang J, et al. Hybrid energy storage devices: Advanced electrode materials and matching principles. Energy Storage Mater, 2019, 21: 22-40

4 Zhou Z, Li Q, Yuan L, et al. Achieving ultrahigh-energy-density in flexible and lightweight all-solid-state internal asymmetric tandem 6.6 V all-in-one supercapacitors. Energy Storage Mater, 2019, 25: 893-902

5 Yuan K, Xu Y, Uihlein J, et al. Straightforward generation of pillared, microporous graphene frameworks for use in supercapacitors. Adv Mater, 2015, 27: 6714-6721

6 Zhao J, Ge C, Zhao Z, et al. Sub-nanometer-scale fine regulation of interlayer distance in $\mathrm{Ni}-\mathrm{Co}$ layered double hydroxides leading to high-rate supercapacitors. Nano Energy, 2020, 76: 105026

7 Peng Z, Huang J, Wang Y, et al. Construction of a hierarchical carbon coated $\mathrm{Fe}_{3} \mathrm{O}_{4}$ nanorod anode for $2.6 \mathrm{~V}$ aqueous asymmetric supercapacitors with ultrahigh energy density. J Mater Chem A, 2019, 7: 27313-27322

8 Huang J, Peng Z, Xiao Y, et al. Hierarchical nanosheets/walls structured carbon-coated porous vanadium nitride anodes enable wide-voltage-window aqueous asymmetric supercapacitors with high energy density. Adv Sci, 2019, 6: 1900550

9 Cui C, Gao Y, Li J, et al. Origins of boosted charge storage on heteroatom-doped carbons. Angew Chem, 2020, 132: 8002-8007

10 Gou Q, Zhao S, Wang J, et al. Recent advances on boosting the cell voltage of aqueous supercapacitors. Nano-Micro Lett, 2020, 12: 98

11 Shao Y, El-Kady MF, Sun J, et al. Design and mechanisms of asymmetric supercapacitors. Chem Rev, 2018, 118: 9233-9280

$12 \mathrm{Li} \mathrm{J}$, An L, Li H, et al. Tunable stable operating potential window for high-voltage aqueous supercapacitors. Nano Energy, 2019, 63: 103848

13 Dou Q, Lu Y, Su L, et al. A sodium perchlorate-based hybrid electrolyte with high salt-to-water molar ratio for safe $2.5 \mathrm{~V}$ car- bon-based supercapacitor. Energy Storage Mater, 2019, 23: 603609

14 Dou Q, Lei S, Wang DW, et al. Safe and high-rate supercapacitors based on an "acetonitrile/water in salt" hybrid electrolyte. Energy Environ Sci, 2018, 11: 3212-3219

15 Xiao D, Dou Q, Zhang L, et al. Optimization of organic/water hybrid electrolytes for high-rate carbon-based supercapacitor. Adv Funct Mater, 2019, 29: 1904136

16 Yu M, Wang Z, Zhang $\mathrm{H}$, et al. Amino functionalization optimizes potential distribution: A facile pathway towards high-energy carbon-based aqueous supercapacitors. Nano Energy, 2019, 65: 103987

17 Song Y, Deng P, Qin Z, et al. A polyanionic molybdenophosphate anode for a $2.7 \mathrm{~V}$ aqueous pseudocapacitor. Nano Energy, 2019, 65: 104010

18 Jabeen N, Hussain A, Xia Q, et al. High-performance 2.6 V aqueous asymmetric supercapacitors based on in situ formed $\mathrm{Na}_{0.5} \mathrm{MnO}_{2}$ nanosheet assembled nanowall arrays. Adv Mater, 2017, 29: 1700804

19 Sahoo R, Pham DT, Lee TH, et al. Redox-driven route for widening voltage window in asymmetric supercapacitor. ACS Nano, 2018, 12: 8494-8505

20 Jabeen N, Xia Q, Savilov SV, et al. Enhanced pseudocapacitive performance of $\alpha-\mathrm{MnO}_{2}$ by cation preinsertion. ACS Appl Mater Interfaces, 2016, 8: 33732-33740

21 Jia $\mathrm{H}, \mathrm{Cai} \mathrm{Y}$, Lin J, et al. Heterostructural graphene quantum dot/ $\mathrm{MnO}_{2}$ nanosheets toward high-potential window electrodes for high-performance supercapacitors. Adv Sci, 2018, 5: 1700887

22 Xu X, Xiong F, Meng J, et al. Vanadium-based nanomaterials: A promising family for emerging metal-ion batteries. Adv Funct Mater, 2020, 30: 1904398

23 Lee $\mathrm{M}$, Wee $\mathrm{BH}$, Hong JD. High performance flexible supercapacitor electrodes composed of ultralarge graphene sheets and vanadium dioxide. Adv Energy Mater, 2015, 5: 1401890

24 Pang H, Dong Y, Ting SL, et al. 2D single- or double-layered vanadium oxide nanosheet assembled 3D microflowers: controlled synthesis, growth mechanism, and applications. Nanoscale, 2013, 5: 7790-7794

25 Bonso JS, Rahy A, Perera SD, et al. Exfoliated graphite nanoplatelets $-\mathrm{V}_{2} \mathrm{O}_{5}$ nanotube composite electrodes for supercapacitors. J Power Sources, 2012, 203: 227-232

$26 \mathrm{Lu} \mathrm{X}, \mathrm{Yu} \mathrm{M}$, Zhai T, et al. High energy density asymmetric quasisolid-state supercapacitor based on porous vanadium nitride nanowire anode. Nano Lett, 2013, 13: 2628-2633

27 Zheng J, Zhang $\mathrm{Y}$, Meng $\mathrm{C}$, et al. $\mathrm{V}_{2} \mathrm{O}_{3} / \mathrm{C}$ nanocomposites with interface defects for enhanced intercalation pseudocapacitance. Electrochim Acta, 2019, 318: 635-643

28 Goodenough JB. Anomalous properties of the vanadium oxides. Annu Rev Mater Sci, 1971, 1: 101-138

29 Xia C, Alshareef HN. Self-templating scheme for the synthesis of nanostructured transition-metal chalcogenide electrodes for capacitive energy storage. Chem Mater, 2015, 27: 4661-4668

30 Zhang $\mathrm{Y}$, Fan $\mathrm{M}$, Hu L, et al. Fabrication of $\mathrm{V}_{2} \mathrm{O}_{3} / \mathrm{C}$ core-shell structured composite and VC nanobelts by the thermal treatment of $\mathrm{VO}_{2} / \mathrm{C}$ composite. Appl Surf Sci, 2012, 258: 9650-9655

31 Li D, Gong Y, Zhang Y, et al. Facile synthesis of carbon nanosphere $/ \mathrm{NiCo}_{2} \mathrm{O}_{4}$ core-shell sub-microspheres for high performance supercapacitor. Sci Rep, 2015, 5: 12903

32 Song $\mathrm{Y}$, Liu $\mathrm{T}$, Li M, et al. Engineering of mesoscale pores in balancing mass loading and rate capability of hematite films for 
electrochemical capacitors. Adv Energy Mater, 2018, 8: 1801784

33 Xiao Y, Xu Y, Zhang K, et al. Coaxial electrospun free-standing and mechanically stable hierarchical porous carbon nanofiber membranes for flexible supercapacitors. Carbon, 2020, 160: 80-87

34 Zhang Y, Fan M, Liu X, et al. Beltlike $\mathrm{V}_{2} \mathrm{O}_{3} @ \mathrm{C}$ core-shell-structured composite: design, preparation, characterization, phase transition, and improvement of electrochemical properties of $\mathrm{V}_{2} \mathrm{O}_{3}$. Eur J Inorg Chem, 2012, 2012(10): 1650-1659

$35 \mathrm{Wu} \mathrm{Y}$, Gao $\mathrm{G}$, Yang $\mathrm{H}$, et al. Controlled synthesis of $\mathrm{V}_{2} \mathrm{O}_{5}$ /MWCNT core/shell hybrid aerogels through a mixed growth and self-assembly methodology for supercapacitors with high capacitance and ultralong cycle life. J Mater Chem A, 2015, 3: 1569215699

36 Yuan K, Lützenkirchen-Hecht D, Li L, et al. Boosting oxygen reduction of single iron active sites via geometric and electronic engineering: nitrogen and phosphorus dual coordination. J Am Chem Soc, 2020, 142: 2404-2412

37 Lian Q, Zhou G, Liu J, et al. Extrinsic pseudocapacitve Li-ion storage of $\mathrm{SnS}$ anode via lithiation-induced structural optimization on cycling. J Power Sources, 2017, 366: 1-8

38 Zhang $\mathrm{K}$, Wei Y, Huang J, et al. A generalized one-step in situ formation of metal sulfide/reduced graphene oxide nanosheets toward high-performance supercapacitors. Sci China Mater, 2020, 63: 1898-1909

39 Pan X, Ren G, Hoque MNF, et al. Fast supercapacitors based on graphene-bridged $\mathrm{V}_{2} \mathrm{O}_{3} / \mathrm{VO}_{x}$ core-shell nanostructure electrodes with a power density of $1 \mathrm{MW} \mathrm{kg}^{-1}$. Adv Mater Interfaces, 2014, 1: 1400398

40 Nagaraju DH, Wang Q, Beaujuge $\mathrm{P}$, et al. Two-dimensional heterostructures of $\mathrm{V}_{2} \mathrm{O}_{5}$ and reduced graphene oxide as electrodes for high energy density asymmetric supercapacitors. J Mater Chem A, 2014, 2: 17146-17152

41 Bai MH, Bian LJ, Song Y, et al. Electrochemical codeposition of vanadium oxide and polypyrrole for high-performance supercapacitor with high working voltage. ACS Appl Mater Interfaces, 2014, 6: 12656-12664

42 Jiang $\mathrm{H}$, Niu $\mathrm{H}$, Yang $\mathrm{X}$, et al. Flexible $\mathrm{Fe}_{2} \mathrm{O}_{3}$ and $\mathrm{V}_{2} \mathrm{O}_{5}$ nanofibers as binder-free electrodes for high-performance all-solid-state asymmetric supercapacitors. Chem Eur J, 2018, 24: 10683-10688

43 Zhai $\mathrm{T}$, Lu X, Ling $\mathrm{Y}$, et al. A new benchmark capacitance for supercapacitor anodes by mixed-valence sulfur-doped $\mathrm{V}_{6} \mathrm{O}_{13-x}$. Adv Mater, 2014, 26: 5869-5875

44 Zhu Q, Zhao D, Cheng M, et al. A new view of supercapacitors: integrated supercapacitors. Adv Energy Mater, 2019, 9: 1901081

Acknowledgements This work was financially supported by the National Natural Science Foundation of China (NSFC, 52073137, 21704038 and 51763018), the NSFC-DFG Joint Research Project (51761135114), the Natural Science Foundation of Jiangxi Province (20192BCB23001 and 20202ZDB01009), and the National Postdoctoral Program for Innovative Talents (BX201700112).

Author contributions Chen $\mathrm{Y}$ and Yuan $\mathrm{K}$ conceived and designed the experiments. Zhang K, Lin Y, Chen L, Huang J, Wang L, Peng M, Tang $\mathrm{X}$ and $\mathrm{Hu} \mathrm{T}$ conducted the experiments, analyzed the data and wrote the manuscript. Chen $\mathrm{Y}$ and Yuan $\mathrm{K}$ supervised the project. All the authors participated in discussions of the research.

Conflict of interest The authors declare no conflict of interest.
Supplementary information Experimental details and supporting data are available in the online version of the paper.

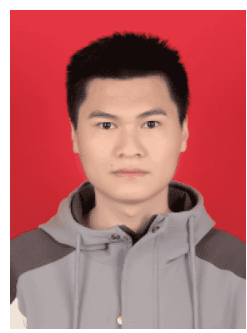

Kaiyang Zhang received his BSc degree from Xinjiang Normal University in 2018. He is currently a Master candidate at the Institute of Polymers and Energy Chemistry (IPEC), Nanchang University. His research interests mainly focus on supercapacitors.

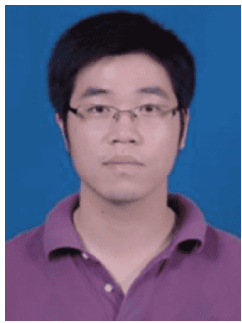

Kai Yuan received his first $\mathrm{PhD}$ degree from Nanchang University in 2016 under the supervision of Professor Yiwang Chen. In 2014, he joined Professor Ullich Scherfs group at the University of Wuppertal in Germany, where he obtained his second $\mathrm{PhD}$ (summa cum laude) in 2017. His current scientific interests include graphene, porous polymer networks, semiconducting (conjugated) polymers, 2D materials, carbon nanomaterials and the corresponding hybrids for electronic and energy-related applications.

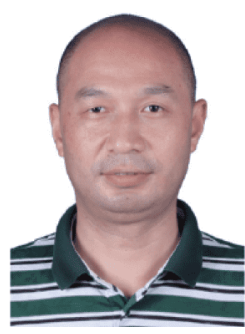

Yiwang Chen is a full professor of chemistry at Nanchang University and Jiangxi Normal University. He received his $\mathrm{PhD}$ from Peking University in 1999 and conducted his postdoctoral work at Johannes Gutenberg-Universität Mainz and Philipps-Universität Marburg in Germany awarded an Alexander von Humboldt fellowship. He joined Nanchang University in 2004. His research interests include polymer solar cells, perovskite solar cells, supercapacitors, electrocatalysis for zinc-air batteries, and intelligent elastomer.

\section{合理设计空心 $\mathrm{V}_{2} \mathrm{O}_{3} / \mathrm{C}$ 集成电极赋予水系超级电容 器2.4 V电压窗口}

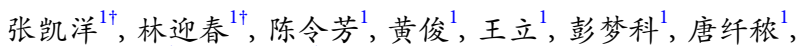
胡婷 $^{2}$, 袁凯 $^{1 *}$, 陈义旺 ${ }^{1,3^{*}}$

摘要 水系超级电容器具有能量密度高, 循环稳定性好, 安全性高 等优势, 但低能量密度阻碍了其进一步应用. 通过一种简单有效的 方法得到具有高能量密度和宽电压的水系超级电容器依旧面临挑 战. 本工作设计了一种三氧化二钒/碳纳米空心球 $\left(\mathrm{H}-\mathrm{V}_{2} \mathrm{O}_{3} / \mathrm{C}\right)$ 电极, 并将其应用于水系超级电容器. 碳的引入可以提高材料的导电性 和稳定性, 同时空心结构有利于提高电化学活性面积, 提供快速的 离子传输通道. 此外, 这种集成电极可同时工作于正极和负极电压 窗口. 因此, $\mathrm{H}-\mathrm{V}_{2} \mathrm{O}_{3} / \mathrm{C}$ 集成电极在-1.1-1.3 V 的电压窗口下具有 $708.6 \mathrm{~F} \mathrm{~g}^{-1}$ 的比容量. 基于其多重储能机制, 得到的水系对称超级 电容器比传统的 (非)对称超级电容器具有更高的电压窗口和能量 密度. 在 $2.4 \mathrm{~V}$ 的宽电压下工作, 当功率密度为 $1204.6 \mathrm{~W} \mathrm{~kg}^{-1}$ 时具有 $96.8 \mathrm{~W} \mathrm{~h} \mathrm{~kg}$ 的高能量密度, 同时具有优良的循环稳定性. 本研究 对电极材料的设计和制备具有一定的启发意义, 为开发宽电压水 系超级电容器开辟了一条新途径. 